\section{The Research Defence Society}

TrE Research Defence Society policy of presenting factual information in readily assimilable forms on 'explosive' topics like immunization, vaccination and animal experiments continues with an excellent pamphlet on vaccination against whooping cough, diphtheria and tetanus (Conquest Pamphlet No. 11. Research Defence Society, 11 Chandos Street, Cavendish Square, London, W.1. 6d.). The methods of immunization against these three conditions and the problems arising in connexion with the procedure are considered together for two reasons: the first is that protective injections against these diseases are now usually given earlier in life than are most others; and the second that these substances are often given all together as a mixture, thus minimizing the number of injections required. The value of the pamphlet is that in no cases are dangers minimized or awkward questions evaded. These are put simply, answered objectively, and include information which indicates where preventive medicine may not always have been effective. The pamphlet should be widely distributed in maternity and child welfare clinics.

\section{Genetic Recombination in Salmonella typhimurium occurring during Transmission of Colicinogeny}

AN interesting item in the annual report of the Lister Institute for 1960 is an investigation by Drs. Ozeki and Howarth into the recombination of chromosomal genes in systems in which colicinogeny is being transmitted. Their results indicate that, in about one pairing in a million, genes believed to be located in the bacterial chromosome (for example, genes regulating various biosynthetic steps and a gene for resistance to streptomycin) undergo recombination. Recombinants can be detected in small numbers whenever colicinogeny-1 is being transmitted at high frequency, and in larger numbers when colicinogeny- $E 1$ is also being transmitted. Many pairs of genes cannot be simultaneously transduced by a single phage particle, probably because they are not close together in the bacterial chromosome, only a very small fraction of which ean be enclosed within a single phage particle. A number of crosses involving such pairs of apparently unlinked genes were made by the newly discovered method of hybridization, and in every instance a fraction of the recombinants was found to have received both pairs of genes concerned from the strain which was transmitting colicinogeny. This suggests that, in this new kind of hybridization, either the whole or at least a large fraction of the chromosomes of the transmitting strain is enabled to recombine with the chromosome of the acceptor strain, in contrast to the situation in phage-mediated transduction. It seems likely that the new method of hybridization may prove of great value in determining the arrangement of the genes along the whole length of the Salmonella chromosome, a problem which could not be investigated with the previously available method of hybridization by phage-mediated transduction.

\section{Nature Conservation in East Anglia}

A Bookler, "Nature and Conservation in East Anglia", produced on the occasion of the Duke of Edinburgh's visit on July 8, 1960, describes briefly the work of the Conservation Corps of the Council for Nature in clearing scrub for the National Trust at Wicken Fen, the Nature Reserve at Havergate Island and Orfordness, and the work of the Field
Studies Council at Flatford Mill (pp. 16. London: The Council for Nature, 1960). This attractive booklet also gives brief accounts of the work of the Council for Nature and the Royal Society for the Protection of Birds as well as of the Nature Conservancy, and is well designed to promote public awareness of our heritage of wild life and the need to conserve it more effectively.

\section{Darwin's Notebooks}

IN Part 3 of "Darwin's Notebooks on Transmutation of Species", Sir Gavin de Beer shows that the contents of the "Third Notebook" owe nothing to Malthus's work (Bull. Brit. Mus. (Nat. Hist.), Historical 2, No. 4. London, 1960). "It is therefore of great importance to note that Darwin hit on the principle of natural selection independently. After a consideration of changes resulting in the formation of new species, he wrote : 'All this agrees well with my view of those forms slightly favoured getting the upper hand and forming species'." Darwin himself realized the historical importance of these lines, because at a later date when he looked through his "Notebook", he wrote at the head of it: "Towards close I first thought of selection owing to struggle". How the stimulus of Malthus's book put Darwin on the scent of natural selection is well brought out in this edited version of his "Third Notebook".

\section{Lancaster Royal Grammar School Natural History Society}

THE extra-mural duties involved in running a society in a grammar school is an arduous task for the masters and boys concerned. Lancaster Royal Grammar School may be rightly proud of its Natural History Society, which has recently celebrated its twenty-first anniversary. The society periodically publishes a magazine, and, in the ninth issue of The New Biologian, the contributions include articles by the masters and boys, records of the Society's activities, etc. The articles include descriptions of biological stations and field study centres and show the value of these in awakening genuine interests among the participating students. One clear difference emerges from the journal and those of natural history societies established in boarding schools: almost invariably in the latter their journals contain some record of original work by boys. Biology masters in grammar schools would do well to examine them.

\section{The Korsakov Journal of Neuropathology and Psychiatry}

Arrangements have been completed for the quarterly publication of an English translation of selected papers from the well-known Soviet periodical, The Korsakov Journal of Neuropathology and Psychiatry. The English edition will begin with the first issue of 1960, and will contain English abstracts of all articles not translated. The translated journal will be published by Pergamon Press, and Dr. W. Ritchie Russell (Oxford) will act as English editor.

\section{American Society for Cell Biology}

A GROUP of cell biologists met in New York on January 9 and again on May 28 of this year, and organized a new society, the purpose of which is to further the development of cell biology and to improve communication among scientists representing diverse disciplines. Membership is expected to include biochemists, biophysicists, cytologists, histologists, 